\title{
A Review of the Effectiveness of Arthroereisis Implant in Adults with Acquired Flatfoot Deformity
}

\author{
Paolo Ceccarini ${ }^{1}$, Rosario Petruccelli ${ }^{1 *}$, Marco Corzani ${ }^{2}$, Lorenzo \\ Maria Di Giacomo ${ }^{1}$, Giuseppe Rinonapoli ${ }^{1}$, Pierluigi Antinolfi ${ }^{1}$ and \\ Auro Caraffa ${ }^{1}$ \\ ${ }^{1}$ SM Misericordia Hospital Orthopaedic and Traumatology Department, University of \\ Perugia, Italy \\ ${ }^{2}$ Villa Maria Private Hospital, Rimini, Italy \\ *Corresponding Author: Rosario Petruccelli, SM Misericordia Hospital \\ Orthopaedic and Traumatology Department, University of Perugia, Italy.
}

Received: November 09, 2021

Published: January 25, 2022

(C) All rights are reserved by Rosario

Petruccelli., et al.

\begin{abstract}
The role of arthroereisis in adult flatfoot has been debated for years. Arthroereisis procedures were originally designed for the treatment of pediatric deformities, that is: correction of the flatfoot while preserving foot function, subtalar joint locking device into the sinus tarsi or tarsal canal. The purpose of this study was to review the literature on arthroereisis implants in adults. The literature was reviewed from 2003 to 2019. 13 articles were included in the study. Most were level 4 evidence. Over all outcomes were good, but the overall study quality was poor. The authors recommend further studies in the topic. Methods: In January 2020 a topical review of the PubMed/MEDLINE, EMBASE database was conducted. This review identified 13 studies focusing on the use of arthroereisis in adults with flatfoot, for a total of 456 feet in 431 patients, with a mean age of 46.3 years and median follow-up of 35 months. Results:: The current evidence for the treatment is limited to retrospective case series. The clinical results are encouraging but the removal of the implant remains controversial. Conclusion: The degree of recommendation in adults is level IV. There is no consensus related to what kind of implant should be indicated. Finally, to definitively validate the success of arthroereisis procedure prospective and comparative studies are indispensable.
\end{abstract}

Keywords: Adult-acquired Flatfoot Deformity; Arthroereisis; Flexible Flatfoot; Posterior Tibial Tendon

\section{Highlights}

- The role of arthroereisis in adult flatfoot has been debated for years.

- $\quad$ The literature was reviewed from 2003 to 2019. 13 articles were included in the study.

- $\quad$ The results published, especially in recent studies, are satisfactory, but the literature is poor.

- The degree of recommendation in adults is level IV.

\section{Introduction}

Adult-acquired flatfoot deformity (AAFD) is a multifactorial pathology characterized by plantarflexion of the talus, collapsed medial arch, and abduction of the forefoot [1-7]. A variety of surgical treatments have been used to correct symptomatic flexible flatfoot with several procedures proposed. When conservative treatments are not effective, surgery is indicated which can include both softtissue and bone procedures. The acknowledgment of the early stages of the disease and posterior tibial tendon degeneration is essential to address the optimal management of the patient [6]. It 
has been well documented that subtalar arthroereisis is a proposed treatment in the treatment of flexible flatfoot in adults, reducing pain, deformity, and instability [4,5]. Despite different ideas regarding optimal technique and the use of implants, the principle of reducing overpronation is commonly accepted [7]. Arthroereisis was first described by Grice in 1952 for correction of paralytic flatfeet in children without affecting foot growth Arthroereisis procedures were originally designed for the treatment of pediatric deformities and generally involved joint- sparing techniques, that is, correction of the flatfoot while preserving foot function [8]. The rationale for this procedure is that placing a subtalar joint locking device into the sinus tarsi or tarsal canal restores and maintains the physiologic alignment between the talus and calcaneus during bone remodeling while correcting the deformity before it turns into a rigid one. In this study we reviewed the literature on the use of arthroereisis procedures in adult flexible flatfoot. The aim of this review is to provide an updated overview of outcomes of arthroereisis procedures in the adults with flexible flatfoot deformity in order to summarize and associate the usefulness of these procedures. Fo- cusing especially on clinical outcomes, studies related to this type of technique were examined in order to evaluate the success of this practice that is, results and complications.

\section{Materials and Methods}

This review was conducted according to the PRISMA guidelines (Preferred Reporting Items of Systematic Reviews) (Figure 1). The PubMed/MEDLINE, EMBASE, and Google Scholar electronic databases were researched from January 2003 to December 2019 separately and independently by the first three authors, using the keywords ("adult" [MeSH Terms] OR "adult" [All Fields]) AND arthroereisis[All Fields]). Every study included in this review was then assigned a level of evidence (I-V), according with the criteria of the Journal of Bone and Joint Surgery $[9,10]$. The studies included in this review encountered the following inclusion criteria: reporting on more than 10 patients, a study population with a minimum age of 18 years, and those with a minimum of 12 months of follow-up.
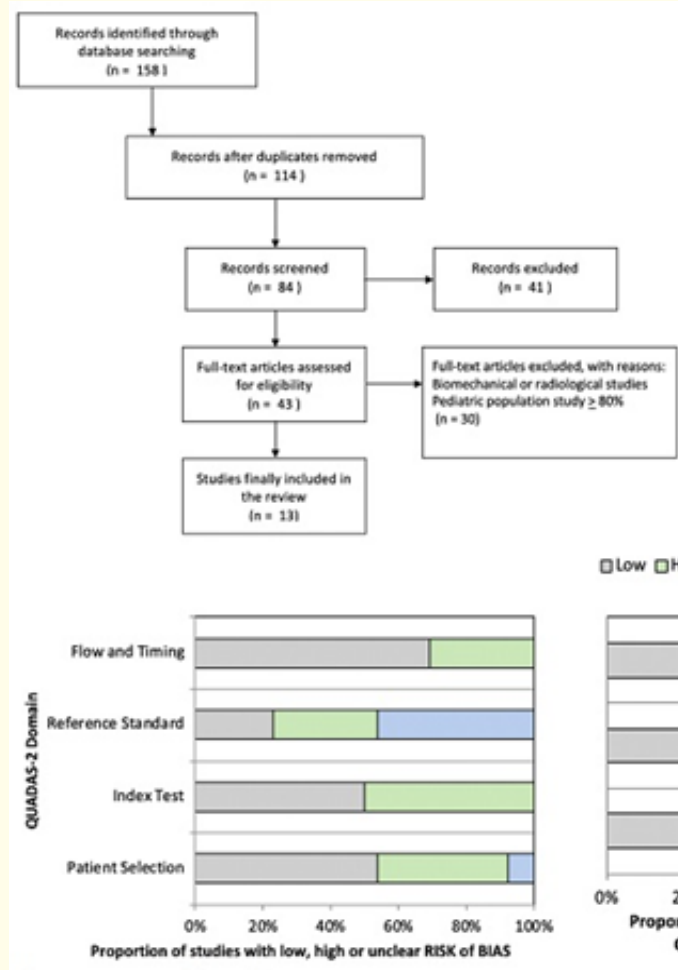

DLow QHigh घUnclear

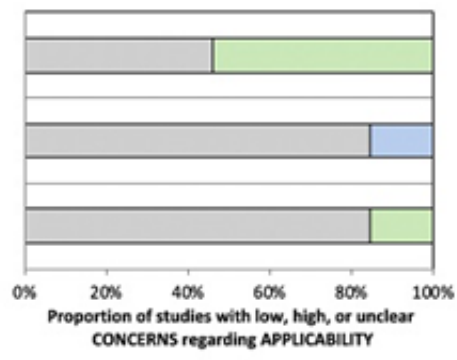

Figure 1: Prisma flow diagram. 
Exclusion criteria were non-English publications without an English translation and case reports or studies that did not provide radiographic measurements. First author individually used the QUADAS-2 tool (Figure 2) to assess the methodological quality of the studies included [11]. The search was carried out in January 2020. After evaluating abstracts and full-text reviews, 13 articles were included in this review, for a total of 456 feet in 431 patients, with a mean age of 46.3 years (range 24, 3y-56, 9) and median follow-up of 35 months (range 15, 1 months-6, 5 years) [12-24]. The 11/13 included studies were Evidence IV Level studies and 2/13 studies included were level of evidence III. All studies were retrospectives. The studies presented different outcome methods: mostly used were The American Orthopaedic Foot and Ankle Society (AOFAS) hindfoot score, reported in 5 of 11 studies. 3 studies have not reported outcomes scores, only radiographic results. The Visual Analog Scale (VAS) for Pain is reported in 4/11 studies. The VAS-FA (foot-ankle) only in one study. All studies included in this review treated patients with symptomatic flexible flatfoot deformity grade II according to Johnson and Storm and Bluman-Myerson Classification, II a is the most frequent type. Authors of included studies used different radiographic parameters, the most used are APTN (anteroposterior talonavicular coverage angle), LTMA (lateral talar-first metatarsal angle), Meary's angle and Kite's angle [25-27].

\begin{tabular}{|c|c|c|c|c|c|c|c|c|}
\hline Author & $\begin{array}{l}\text { level of } \\
\text { evidence }\end{array}$ & $\begin{array}{c}\text { Patient } \\
\text { Selection }\end{array}$ & Index Test & $\begin{array}{l}\text { Reference } \\
\text { Standard }\end{array}$ & $\begin{array}{c}\text { Flow and } \\
\text { Timing }\end{array}$ & $\begin{array}{c}\text { PATIENT } \\
\text { SELECTION }\end{array}$ & $\begin{array}{c}\text { INDEX } \\
\text { TEST }\end{array}$ & $\begin{array}{l}\text { REFERENCE } \\
\text { STANDARD }\end{array}$ \\
\hline Adelman & IV & High & High & High & Low & Low & Low & Low \\
\hline Baker & IV & Low & High & High & High & Low & Low & High \\
\hline Ceccarini & IV & Low & Unclear & High & High & Low & Low & High \\
\hline Cook & IV & High & Unclear & High & Low & High & Low & Low \\
\hline Needleman & IV & Unclear & Unclear & High & High & Low & Low & High \\
\hline Ozan & IV & High & Low & High & Low & Low & Low & High \\
\hline Saxena & III & Low & Unclear & Low & Low & Low & Unclear & Low \\
\hline Saxena & III & Low & Unclear & High & Low & Low & Low & High \\
\hline Viladot & IV & High & High & High & Low & Low & Low & High \\
\hline Viladot & IV & Low & Low & High & High & Low & Low & Low \\
\hline Wallex & IV & High & Unclear & High & Low & High & Unclear & Low \\
\hline Yasui & IV & Low & Low & High & Low & Low & Low & Low \\
\hline Zhu & IV & Low & High & High & Low & Low & Low & High \\
\hline
\end{tabular}

Figure 2: Quality assessment (QUADAS-2) of included studies on anthroereisis in adults.

\section{Results and Discussion}

In all studies included, excepted Ozan., et al. the arthroereisis were combined with additional procedures, FDL transfer and PTT tensioning were widely used $[1,8,28]$. AOFAS Score. Postoperative AOFAS scores were reported in 5 studies. The mean score at final follow-up was 82.2 (range 75 to 87). Yasui., et al. reported a median FAOS (Foot Ankle Outcome Score) of 69 at final follow-up [21]. About VAS Score, three studies reported VAS scores with an average of 2.7 points at the final follow-up. Ceccarini., et al. reported a mean VAS-FA of 83 at final follow-up [24] (Table 1).
10 of 13 studies reported complications in the results. The main objective was to assess whether there were complications in the use of arthroereisis in adults and surgery-related complications were observed (Table 2). In total, $23,4 \%(n=82)$ rate of complications is reported. The most frequent complication was sinus tarsi pain, which reported in an average $13,1 \%$ of all cases treated; in total 60 sinus tarsi pain are reported $(73,2 \%$ of complications). More than $90 \%$ of the authors describe the resolution of the symptoms at the removal of the arthroereisis $[4,14,17,20,21]$. 
28

\begin{tabular}{|c|c|c|c|c|c|c|c|c|}
\hline Authors & $\begin{array}{c}\text { Level of } \\
\text { evidence }\end{array}$ & Year & Procedures & $\begin{array}{l}\text { Patients/ } \\
\text { feet }\end{array}$ & $\begin{array}{l}\text { Follow-up } \\
\text { (months) }\end{array}$ & $\begin{array}{l}\text { Mean } \\
\text { age }\end{array}$ & $\begin{array}{l}\text { Classi- } \\
\text { fication } \\
\text { Stage }\end{array}$ & $\begin{array}{l}\text { post-operative out- } \\
\text { comes } \\
\text { (AOFAS-FAOS-VAS) }\end{array}$ \\
\hline Yasui & IV & 2016 & $\begin{array}{l}\text { Arthroeresis + PTT tendos- } \\
\text { copy }\end{array}$ & $13 / 13$ & 29.5 & $\begin{array}{c}37.3 \\
\text { yrs }\end{array}$ & 12 II A & $\begin{array}{c}\text { FAOS: 78.5.; 68.2; 83.3; } \\
65 ; 48.6 \\
\text { VAS } 1.7\end{array}$ \\
\hline Ozan & IV & 2015 & Arthroeresis & $16 / 26$ & 15.1 & 24.3 & / & $\begin{array}{c}\text { AOFAS: } 75 \\
\text { VAS: } 4.1\end{array}$ \\
\hline Zhu & IV & 2014 & $\begin{array}{c}5 \text { arthroereises alone } \\
11 \text { FDL transfer } \\
8 \text { medial slide calcaneal } \\
\text { osteotomy and FDL transfer } \\
2 \text { first tarsometatarsal joint } \\
\text { fusion } \\
6 \text { Cotton procedure } \\
13 \text { gastrocnemius release } \\
\text { or percutaneous Achilles } \\
\text { release }\end{array}$ & $22 / 24$ & 29.7 & 48.8 & $\begin{array}{l}12 \text { IIA1 } \\
6 \text { II A2 } \\
2 \text { II C }\end{array}$ & AOFAS 85.6 \\
\hline Viladot & IV & 2016 & $\begin{array}{c}\text { Arthroeresis }+43 \% \text { Achilles } \\
\text { legnhtening - Striping PTT } \\
41 \% \text { - FDL Transfer 27\% - } \\
\text { FDL augmentation 30\%. }\end{array}$ & $35 / 37$ & 47,5 & 54,8 & 37 IIA1 & $\begin{array}{c}74 \% \text { Excellent } \\
11 \% \text { satisfied } \\
15 \% \text { dissatisfied }\end{array}$ \\
\hline $\begin{array}{l}\text { Cecca- } \\
\text { rini }\end{array}$ & IV & 2017 & $\begin{array}{l}\text { Arthroeresis + PTT ad- } \\
\text { vancement }\end{array}$ & $29 / 31$ & 34.1 & 46.4 & $\begin{array}{l}20 \text { IIA1 } \\
11 \text { IIA2 }\end{array}$ & $\begin{array}{l}\text { AOFAS } 81.9 \\
\text { VAS-FA } 83.2 \\
\end{array}$ \\
\hline Saxena & III & 2016 & $\begin{array}{l}\text { Arthroeresis + } 62 \% \text { EGR - } \\
28 \% \text { calcaneal osteotomy }\end{array}$ & $100 / 104$ & 6.5 years & 53.3 & / & / \\
\hline $\begin{array}{l}\text { Adel- } \\
\text { man }\end{array}$ & IV & 2008 & $\begin{array}{l}\text { Arthroeresis + EGR +FDL } \\
\text { transfer }\end{array}$ & $10 / 10$ & 29 & 56.9 & 10 IIB & / \\
\hline Walley & IV & 2018 & Arthroeresis + MDCO & $15 / 15$ & 4.47 years & 51.4 & $15 \mathrm{II}$ & $\begin{array}{c}\text { VAS } 2.44 \\
\text { SF-36 } 75.4\end{array}$ \\
\hline Cook & IV & 2011 & Arthroeresis + fdl transfer & $66 / 66$ & 12 & 30.8 & / & / \\
\hline Viladot & IV & 2003 & $\begin{array}{l}\text { Arthroeresis }+7 \text { tenosyno- } \\
\text { vectomy }+12 \text { fdl transfer }\end{array}$ & $19 / 19$ & 27.31 & 55.6 & 13/19 II & AOFAS 81.6 \\
\hline $\begin{array}{l}\text { Needle- } \\
\text { man }\end{array}$ & IV & 2006 & $\begin{array}{l}\text { Arthroereisis + Achilles } \\
\text { tendon lengthening + 13/28 } \\
\text { fdl transfer }\end{array}$ & $23 / 28$ & 44 & 51 & $28 \mathrm{II}$ & AOFAS 87 \\
\hline Saxena & III & 2016 & $\begin{array}{l}\text { Arthroereisis + calcaneal } \\
\text { osteotomy }\end{array}$ & $\begin{array}{c}30 / 31 \\
17 / 31 \\
\text { Arthro- } \\
\text { ereisis }\end{array}$ & 2 years & 36 & & AOFAS 93.2 \\
\hline Baker & IV & 2012 & Arthroereisis + fdl transfer & $66 / 66$ & 50 & 30 & / & / \\
\hline
\end{tabular}

Table 1: Summary data of included studies.

FDL: Flexor Digitorum Longus; EGR: Endoscopic Gastrocnemius Recession; PTT: Posterior Tibial Tendon; MDCO: Medial Displacement Calcaneal Osteotomy. 


\begin{tabular}{|c|c|c|c|c|}
\hline Author & N. patients/feet & Complications $\mathrm{N}$ feet (\%) & Implant removal & Complications \\
\hline Yasui, 2016 & $13 / 13$ & / & $3 / 13$ & \\
\hline Ozan, 2015 & $16 / 26$ & $4 / 26(15.3 \%)$ & $3 / 26$ & $\begin{array}{c}3 \text { sinus tarsi pain } \\
1 \text { lost fixation }\end{array}$ \\
\hline Zhu, 2014 & $22 / 24$ & $7 / 24(29.1 \%)$ & $\begin{array}{l}\text { 14/24 (recommended } \\
\text { after 18months) }\end{array}$ & $\begin{array}{l}6 \text { sinus tarsi pain } \\
1 \text { recurrence }\end{array}$ \\
\hline Ceccarini, 2017 & $29 / 31$ & $7 / 31(22.5 \%)$ & $3 / 31$ & $\begin{array}{c}5 \text { sinus tarsi pain (resolved after } \\
6 \text { months) } \\
1 \text { stress fracture } \\
1 \text { insufficient correction }\end{array}$ \\
\hline Viladot, 2016 & $35 / 37$ & $15 / 37(40 \%)$ & $13 / 37$ & $\begin{array}{c}5 \text { sinus tarsi pain after removal } \\
1 \text { CRPS } \\
1 \text { overcorrection }\end{array}$ \\
\hline Saxena, 2016 & $100 / 104$ & $23 / 104(22 \%)$ & $23 / 104$ & $\begin{array}{c}4 \text { implant dislocation } \\
17 \text { sinus tarsi pain }\end{array}$ \\
\hline Cook,2011 & $66 / 66$ & Not reported & $22 / 66$ & Not reported \\
\hline Walley, 2018 & $15 / 15$ & $1 / 15(6.6 \%)$ & $1 / 15$ & 1 sinus tarsi pain \\
\hline Needleman, 2006 & $23 / 28$ & $13 / 28(46 \%)$ & $11 / 28$ & 13 sinus tarsi pain \\
\hline Viladot, 2003 & $19 / 19$ & $2 / 19(10.5 \%)$ & $2 / 19$ & 2 sinus tarsi pain \\
\hline Saxena, 2016 & $17 / 17$ & Not reported & $1 / 17$ & \\
\hline Baker, 2012 & $66 / 66$ & $10 / 66(15 \%)$ & $10 / 66$ & 10 sinus tarsi pain \\
\hline TOTAL & $431 / 456$ & $82 / 350(23.4 \%)$ & $96 / 446$ & $60 / 456$ sinus tarsi pain $(13.1 \%)$ \\
\hline
\end{tabular}

Table 2: Rate of Complications and Implant removal. CRPS : Complex pain regional syndrome.

No one of the authors reported major complications, but in one case a CPRS (Complex pain regional syndrome) was observed, and this could be considered a major complication. Ceccarini., et al. reported a case of stress fracture of the IV metatarsal and Saxena., et al. observed 4 dislocations of the implant. Ozan reported one of failure fixation, Viladot evidenced one over correction and Zhu reported a one case of recurrence. An interesting finding is the number of implant removal procedures; these procedures were performed in 96 patients out of 446 feet (21,6\% of treated feet). 9 of 13 included studies reported radiographic results. In this review, we considered only measurements at final follow-up (not available in all studies pre-operative values). In 8 studies reported measures of the APTN (anteroposterior talonavicular coverage angle), the mean value was $6.6^{\circ}$, observing a significant improvement in all variables other than the T-N congruence postoperatively. Furthermore, other radiographic parameters reported are very heterogeneous. Ozan., et al. evidenced a LTC $33.2^{\circ} \pm 5^{\circ} .3$. The Calcaneal pitch reported is from $14.6^{\circ} \pm 2.7$ to $20.2 \pm 3.0$. The Meary's angle recordered is from $3.3^{\circ} \pm 3^{\circ}$ to $4,3^{\circ}$. The post-operative Kite angle range is from $15,2^{\circ}$ to $17.7 \pm 5^{\circ}$. LTMA value reported is from 1,6 to $7,6^{\circ}$. The results of the other radiographic parameters used are shown in table 3. 


\begin{tabular}{|c|c|c|c|c|c|c|c|c|}
\hline $\begin{array}{l}\text { Radiographic } \\
\text { parameters }\end{array}$ & LTMA $^{\circ}$ & LTC $^{\circ}$ & $\begin{array}{c}\text { Calcaneal } \\
\text { pitch }^{\circ}\end{array}$ & APTN & $\begin{array}{c}\text { Cuneiform } \\
\text { to ground } \\
\text { distance }\end{array}$ & $\begin{array}{l}\text { Meary's } \\
\text { angle }^{\circ}\end{array}$ & $\begin{array}{l}\text { Kite's } \\
\text { angle }^{\circ}\end{array}$ & $\begin{array}{c}\text { Dijan-Annonier } \\
\text { Costa Bertani }\end{array}$ \\
\hline Ozan, 2015 & & $33.2^{\circ} \pm 5.3^{\circ}$ & $14.6^{\circ} \pm 2.7^{\circ}$ & $2.6^{\circ} \pm 1.5^{\circ}$ & & $3.3^{\circ} \pm 3^{\circ}$ & $17.7^{\circ} \pm 5^{\circ}$ & \\
\hline Zhu, 2014 & $1.6^{\circ}$ & & & $11.2^{\circ}$ & & & & \\
\hline Cook, 2011 & $7.6^{\circ}$ & & $17.7^{\circ}$ & $7.8^{\circ}$ & & & $16.3^{\circ}$ & \\
\hline Walley, 2018 & 6.8 & & & 4.8 & & & & \\
\hline Viladot, 2003 & & & & & & & $\begin{array}{l}-8.7^{\circ} \text { vs pre- } \\
\text { operative }\end{array}$ & $\begin{array}{c}-14.3^{\circ} \text { vs preopera- } \\
\text { tive }\end{array}$ \\
\hline
\end{tabular}

Table 3: Radiographic Parameters in the studies. LTMA: Lateral Talar-First Metatarsal Angle, LTC: Lateral Talocalcaneal Angle; APTN: Anteroposterior Talonavicular Coverage Angle.

\section{Discussion}

The main aim of this review was to provide information for the use of the arthroereisis in adults and if its use is supported by the current literature. Arthroereisis was originally planned for the treatment of pediatric and adolescent flexible flatfoot $[10,16,23]$.

The acquired flatfoot in adults is frequent and numerous surgical treatments are proposed for the correction of this condition, without consensus regarding best treatment [29-41]. Subtalar Arthroereisis is usually suggested to correct the stage IIA (hindfoot valgus) restoring the position of the calcaneus (Figure 3). The implant technique has been described, but there is a lack of understanding about the mechanism of re-alignment. While the mechanical effect is well known, a hypothetical proprioceptive effect has never been clearly demonstrated [7,8,14]. However, this hypothesis has never been proved by any basic or clinical study. Although only the study of Ceccarini., et al. compared the different types of arthroereisis implants (with no significant differences in terms of functional results), sinus tarsi and tarsi canal implants are more expensive than calcaneo-stop techniques. When comparing different implants, it seems that the calcaneo-stop procedures have lower extrusion rates, unfortunately, there is no level one study in the literature available to prove which is best. Ortiz., et al. in a recent publication reported that regarding the implant design or material, the rationale for this technique is that introduction of a calcaneal motion locking device into the sinus tarsi reestablishes and preserves the physiologic orientation between the talus and calcaneus during bone remodeling while correcting the deformity $[20,22,23]$. Apparently, these locking devices do not negatively affect the biomechanics of the subtalar joint or alter the normal closed kinetic chain mechanics while limiting excessive hindfoot pronation. In our review, most of the authors preferred using associated procedures to give strength and stability to the correction of a flatfoot deformity. The most used procedure is the FDL (flexor digitorum longus) transfer and PTT (posterior tibial tendon) advancement, and percutaneous Achilles release. The rationale of this procedures have to be clarified, nevertheless, many authors believe that flatfoot caused by dysfunction PTT can be better resolved by correcting the valgus of the heel through the subtalar joint rather than by a calcaneal osteotomy [7,14-17,20-23]. Actually the literature evidenced different aspects of arthroeresis: compared with open traditional surgery (calcaneal osteotomy and FDL transfer) it showed lower invasiveness, decreased post-operative edema, shorter hospital stays, possibility of performing associated soft-tissue and bony procedures. However this kind of treatment showed different drawbacks, in fact it is associated with a lack of evidence and uncertain data regarding implant removal rate, the need (and timing) of removal in absence of symptoms, the complication rate, comparison between implants, long-term results. In adults, the procedure is not sufficient to perform alone, whereas it can be useful 

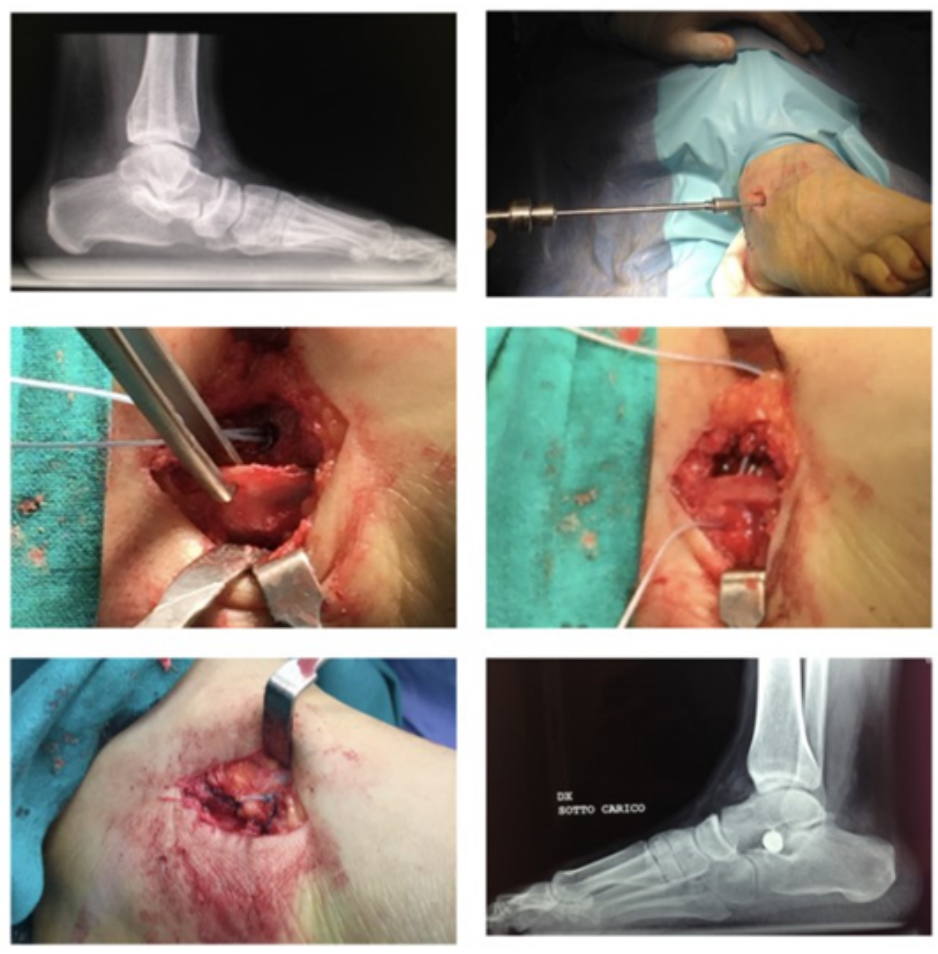

Figure 3

with soft-tissue and bony procedures in order to support the correction effect and to support the tibialis posterior tendon repair. In conclusion, the technique is used as complementary procedure in conjunction with osteotomies and soft tissue reconstruction. Globally, complications may be divided into four main categories, including the consequences of inappropriate indications (unstable midtarsal joint, arthritis, rigid equinus), technical error (extrusion, over- or under-correction), adaptation/irritation (painful sinus tarsitis, peronealspasm, soft-tissue entrapment), and biomaterial failure (wear or breakage). In the past authors suggested the concerning about the device removal, they proposed that an implant should be maintained in place for at least two years to allow adequate bone and soft tissue adaptation. Actually, the main debate in this procedure for this type of deformity is still if high rate of removal implant is a complication. In most of cases the removal of implant it solves the pain. In any event, no precise data are available about the minimum time required to mantain long-lasting correction. In terms of secondary outcome measures, most studies showed good results, however, we suggest that more validated outcome mea- sures and more specific radiographic criteria are necessary. The rationale of the arthroereisis in adults is difficult to define and diagnose. Therefore, well-defined guidelines for analysis and treatment are hard to recommend. For the similar reason, this review is important for provide an outline of findings in literature to present. The QuadaS 2 could causes some limitations. This tool is dedicated on assessing the quality of diagnostic accuracy studies; the results of this instrument are not frankly applicable to other research questions. This Quadas emphasizes the absence of a reliable standard reference test. The level of evidence of this review is limited by the poor methodological quality of the included ones. Furthermore, most of the involved studies distributed with small populations. The surgeons with this surgery procedure manages to obtain the rising of the talus and the correction of the Meary line in a more significant way than just the heel osteotomy and avoids the use of more invasive corrective osteotomies in flexible flat feet. Nevertheless, this study is clinically relevant because it offers an overview of the current literature available; it also emphasizes the need for high-quality studies with clearly defined inclusion criteria 
and validated outcome measurements.. A series of good results have been reported but it is extremely difficult to extract reliable data about the true role of a subtalar implant and its real contribution to final deformity correction. The role of arthroereisis in the adults with flexible acquired flatfoot appears to provide good outcomes with regard to patient satisfaction. However, the patient needs to be advised about the potential pain after the arthroereisis, because even when this repair is performed under best conditions, the incidence of sinus tarsi pain is a common complication and the implant removal is a frequent option. Actually no data are available at the moment to guide the surgeons to the choice of implant removal, no data for the timing of the removal and the risks after its removal. No data are available at the moment to evidence the results and clinical outcomes or radiographic findings after implant removal; a prospective studies can be useful to carry out information and indications about it. In the case of an adult foot already biomechanically defined, in our opinion the endorthesis should not be removed in the asymptomatic patient; an early removal before one year could lead to a recurrence of the deformity. However, as already expressed by the work of Viladot., et al. the correction obtained, with a removal after at least 18 months, tends to remain even in the feet where the screw has been removed. There are several controversial and still unanswered points in the use of arthroeresis in adults. The removal of the implant, expected in the child, can be considered a complication in the adult as it could lead to a reduction in the correction; many times an oversized implant could cause conflict on the sub-astragalic joint, so we usually prefer to use a smaller size to reduce this risk. In any case, when the implant was removed, we did not observe a reappearance of the symptoms. There are numerous types of arthroeresis and each author reports results of the implant he usually uses, so a comparison is currently not possible. The results published, especially in the most recent studies, are most satisfactory, but the literature is still poor. In performing subtalar arthroereisis surgeons usually rely on personal experience or on suggestions in the literature rather than a structured scientific report. This is probably the main reason why nowadays the literature available on this topic looks so heterogeneous. There is no consensus related to what kind of arthoerereisis should be indicated. The results published, especially in the most recent studies, are very satisfactory, but the literature is still poor.

\section{Conclusion}

Therefore, on the basis of the conclusions of this study, the grade of recommendation for subtalar arthroereisis should be con- sidered as C (according to factors that include the risk of bias, precision of estimates, the consistency of the results, and the level of evidence). Demonstrating the rationale and effectiveness of adult arthoerereisis even over a long period of time is the goal of future studies on the topic. Prospective randomized studies on the topic and in particular a comparison with the osteotomy of calcaneus in grade IIA and the assessment of recurrence of deformity in patients who have removed the implant are required.

According to the data here shown, precise comparative and prospective studies are needed to elucidate the real advantages and indications of such devices

\section{Acknowledgements}

None.

\section{Conflict of Interest}

On behalf of all authors, the corresponding author states that there is no conflict of interest.

\section{Bibliography}

1. Bluman E., et al. "Posterior tibial tendon rupture: a refined classification system". Foot and Ankle Clinics of North America 12 (2007): 233-249.

2. Deland JT. "Adult - Acquired flatfoot deformity". Journal of the American Academy of Orthopaedic Surgeons 16 (2008): 399406.

3. Myerson MS. "Adult acquired flatfoot deformity: treatment of dysfunction of the posterior tibial tendon". Instructional Course Lectures 46 (1997): 393-405.

4. Needleman RL. "A surgical approach for flexible flatfeet in adults including a subtalar arthroereisis with the MBA sinus tarsi implant". Foot and Ankle International (2006).

5. Ortiz CA., et al. "Arthroereisis: What Have We Learned?". Foot and Ankle Clinics 23.3 (2018): 415-434.

6. Pinney SJ and Lin SS. "Current concept review: acquired adult flatfoot deformity”. Foot and Ankle International 27 (2006): 66-75.

7. Bernasconi A., et al. "The role of arthroereisis of the subtalar joint for flatfoot in children and adults". EFORT Open Review 2.11 (2017): 438-446.

Citation: Rosario Petruccelli., et al. "A Review of the Effectiveness of Arthroereisis Implant in Adults with Acquired Flatfoot Deformity". Acta Scientific Orthopaedics 5.2 (2022): 25-34. 
8. Arangio GA and Salathe EP. "A biomechanical analysis of posterior tibial tendon dysfunction, medial displacement calcaneal osteotomy and flexor digitorum longus transfer in adult acquired flat foot". Clinical Biomechanics (Bristol, Avon) 24.4 (2009): 385-390.

9. Moher D., et al. "Preferred reporting items for systematic reviews and metaanalyses: the PRISMA statement". PLoS Medicine 6 (2009): e123-e130.

10. Wright JG., et al. "Grades of recommendation". Journal of Bone and Joint Surgery 87.9 (2005): 1909-1910.

11. Whiting PF., et al. "QUADAS-2: a revised tool for the quality assessment of diagnostic accuracy studies". Annals of Internal Medicine 155.8 (2011): 529-536.

12. Adelman VR., et al. "Radiographic evaluation of endoscopic gastrocnemius recession, subtalar joint arthroereisis, and flexor tendon transfer for surgical correction of stage II posterior tibial tendon dysfunction: a pilot study". Journal of Foot and Ankle Surgery 47.5 (2008): 400-408.

13. Baker JR., et al. "Retrospective analysis of the survivability of absorbable versus nonabsorbable subtalar joint arthroereisis implants". Foot and Ankle Specialist 6.1 (2013): 36-44.

14. Ceccarini P., et al. "The arthroereisis procedure in adult flexible flatfoot grade IIA due to insufficiency of posterior tibial tendon". Foot and Ankle Surgery 24.4 (2018): 359-364.

15. Cook EA., et al. "Identifying risk factors in subtalar arthroereisis explantation: a propensity-matched analysis". Journal of Foot and Ankle Surgery 50.4 (2011): 395-401.

16. Lu W., et al. "The arthroereisis procedure in adult flexible flatfoot grade IIA due to insufficiency of posterior tibial tendon". Foot and Ankle Surgery 24.2 (2018): 171.

17. Ozan F., et al. "Symptomatic flexible flatfoot in adults: subtalar arthroereisis". Therapeutics and Clinical Risk Management 11 (2015): 1597-602.

18. Saxena A and Patel R. "Medial Displacement Calcaneal Osteotomy: A Comparison of Screw Versus Locking Plate Fixation". Journal of Foot and Ankle Surgery 55.6 (2016): 1164-1168.

19. Saxena A., et al. "Subtalar Arthroereisis Implant Removal in Adults: A Prospective Study of 100 Patients". Journal of Foot and Ankle Surgery 55.3 (2016): 500-503.

20. Viladot R., et al. "Subtalar arthroereisis for posterior tibial tendon dysfunction: a preliminary report". Foot and Ankle International 24.8 (2003): 600-606.
21. Viladot Voegeli A., et al. "Results of subtalar arthroereisis for posterior tibial tendon dysfunction stage IIA1. Based on 35 patients". Foot and Ankle Surgery 24.1 (2018): 28-33.

22. Yasui Y., et al. "Use of the arthroereisis screw with tendoscopic delivered platelet-rich plasma for early stage adult acquired flatfoot deformity". International Orthopaedics 41.2 (2017): 315-321.

23. Zhu Y and Xu XY. "Treatment of Stage II Adult Acquired Flatfoot Deformity With Subtalar Arthroereises". Foot and Ankle Specialist 8.3 (2015): 194-202.

24. Kitaoka HB., et al. "Clinical rating systems for the ankle-hindfoot, midfoot, hallux, and lesser toes". Foot and Ankle International 15 (1994): 349-353.

25. Richter M., et al. "A new foot and ankle outcome score: questionnaire based, subjective, Visual-Analogue-Scale, validate and computerized". Foot and Ankle Surgery 12.4 (2006): 191199.

26. Wong DW., et al. "Biomechanical consequences of subtalar joint arthroereisis in treating posterior tibial tendon dysfunction: a theoretical analysis using finite element analysis". Computer Methods in Biomechanics and Biomedical Engineering 20.14 (2017): 1525-1532.

27. Grant WP., et al. "Beaming the columns for Charcot diabetic foot reconstruction: a retrospective analysis". Journal of Foot and Ankle Surgery 50.2 (2011): 182-189.

28. Brancheau SP., et al. "An analysis of outcomes after use of the Maxwell-Brancheau Arthroereisis implant". Journal of Foot and Ankle Surgery 51.1 (2012): 3-8.

29. Chang TJ and Lee J. "Subtalar joint arthroereisis in adult-acquired flatfoot and posterior tibial tendon dysfunction". Clinics in Podiatric Medicine and Surgery 24.4 (2007): 687-697.

30. Corpuz M., et al. "Fracture of the talus as a complication of subtalar arthroereisis". Journal of Foot and Ankle Surgery 51.1 (2012): 91-94.

31. Dellon AL., et al. "Sinus tarsi denervation: clinical results". Journal of the American Podiatric Medical Association 95.2 (2005): 108-113.

32. Fernández de Retana P., et al. "Is there a role for subtalar arthroereisis in the management of adult acquired flatfoot?". Foot and Ankle Clinics 17.2 (2012): 271-281. 
33. Flynn J., et al. "Bridle procedure combined with a subtalar implant: a case series and review of the literature". Foot and Ankle Specialist 8.1 (2015): 29-35.

34. Garras DN., et al. "Outcome of modified Kidner procedure with subtalar arthroereisis for painful accessory navicular associated with planovalgus deformity". Foot and Ankle International 33.11 (2012): 934-939.

35. Lui TH. "Endoscopic assisted posterior tibial tendon reconstruction for stage 2 posterior tibial tendon insufficiency". Knee Surgery, Sports Traumatology, Arthroscopy 15.10 (2007): 1228-1234.

36. Schon LC. "Subtalar arthroereisis: a new exploration of an old concept”. Foot and Ankle Clinics 12 (2007): 329-339.

37. Shah NS., et al. "Subtalar Arthroereisis Survey: The Current Practice Patterns of Members of the AOFAS". Foot and Ankle Specialist 8.3 (2013): 180-185.

38. Soomekh DJ and Baravarian B. "Pediatric and adult flatfoot reconstruction: subtalar arthroereisis versus realignment osteotomy surgical options". Clinics in Podiatric Medicine and Surgery 23.4 (2006): 695-708.

39. Walley KC., et al. "Short- to Mid-Term Outcomes Following the Use of an Arthroereisis Implant as an Adjunct for Correction of Flexible, Acquired Flatfoot Deformity in Adults". Foot and Ankle Specialist 12.2 (2019): 122-130.

40. Xu J., et al. "Comparison of Extraosseous Talotarsal Stabilization Implants in a Stage II Adult-Acquired Flatfoot Model: A Finite Element Analysis". Journal of Foot and Ankle Surgery 56.5 (2017): 1058-1064.

41. Yen-Douangmala D., et al. "Subtalar arthroereisis and its role in pediatric and adult population". Clinics in Podiatric Medicine and Surgery 29.3 (2012): 383-390.

\section{Assets from publication with us}

- Prompt Acknowledgement after receiving the article

- Thorough Double blinded peer review

- Rapid Publication

- Issue of Publication Certificate

- High visibility of your Published work

Website: www.actascientific.com/

Submit Article: www.actascientific.com/submission.php

Email us: editor@actascientific.com

Contact us: +919182824667

Citation: Rosario Petruccelli., et al. "A Review of the Effectiveness of Arthroereisis Implant in Adults with Acquired Flatfoot Deformity". Acta Scientific Orthopaedics 5.2 (2022): 25-34. 